\title{
Synthesis of $\mathrm{SiC}$ from rice husk in a plasma reactor
}

\author{
S K SINGH, B C MOHANTY and S BASU* \\ *Materials Science Centre, Indian Institute of Technology, Kharagpur 721 302, India \\ Regional Research Laboratory, Bhubaneswar 751 013, India
}

\begin{abstract}
A new route for production of $\mathrm{SiC}$ from rice husk is reported by employing thermal plasma technique. The formation of $\beta-\mathrm{SiC}$ is observed in a short time of $5 \mathrm{~min}$. The samples are characterized by XRD and SEM.
\end{abstract}

Keywords. Thermal plasma; rice husk; silicon carbide.

\section{Introduction}

India is one of the largest rice producing countries in the world. Therefore, a large quantity of rice husk is generated as a by-product of rice milling. It has been estimated that 18.3 million tons of rice husk is produced every year (Panigrahi and Overand 1997). At present the rice husk is considered as an agricultural waste. Burning has been the primary means of disposal. Not only does burning create pollution problems but the extremely fine silica ash is also toxic and thus constitutes a health hazard. Even careful incineration procedures cannot completely eliminate this airborne silica. Thus, burning with its attendant problems of air pollution and ash disposal has proven to be an unsatisfactory solution. Fortunately, rice husk contains the necessary carbon and silica, intimately dispersed, to provide a nearly ideal source material for production of $\mathrm{SiC}$, an industrially important ceramic material. Rice husk was first used by Cutler (1973) as a starting material for the production of silicon carbide. Since the rice husk route appears to be promising, much attention has been paid to it (Mansour and Hanna 1979; Nutt 1988; Patel 1991; Ray et al 1991; Singh et al 1993, 1995; Romera and Reinso 1996; Moustafa et al 1997; Krishnarao et al 1998; Padmaja and Mukunda 1999; Janghorban and Tazesh 1999; Panigrahi et al 2001). Almost all the processes investigated so far involve two process steps i.e. (i) cooking at lower temperature $\left(400-800^{\circ} \mathrm{C}\right)$ in a controlled manner to remove volatiles and (ii) reacting the cooked rice husk at high temperature $\left(>1300^{\circ} \mathrm{C}\right)$ to form $\mathrm{SiC}$. In a novel approach, we have attempted to prepare $\mathrm{SiC}$ from rice husk in a single step and this paper gives the detailed account of the work.

\section{Experimental}

A single step was adopted to prepare SiC directly from raw rice husk in an indigenously developed pot type extended

\footnotetext{
*Author for correspondence
}

arc plasma reactor using graphite electrodes. Figure 1 shows the schematic diagram of the reactor assembly. A graphite crucible containing the charge acted as the bottom electrode. The extended arc was formed by the movement of the top graphite electrode with an axial hole through which the argon plasma forming gas was introduced. Experiments were carried out in batch operations and experimental conditions such as power and time were varied. A typical experimental condition is as follows: Argon gas flow, 2 lpm; current, $300 \mathrm{~A}$; load voltage, $50 \mathrm{~V}$. After the end of the experiment argon gas was allowed to pass for $1 \mathrm{~h}$ and then the crucible was allowed to cool to room temperature. The plasma treated sample was found to be green in colour and fragile in nature, thus could easily ground in a mortar and pestle. The sample was then characterized by XRD (Philips ADP 1700) for phase analysis and SEM (JEOL 35 CF and JEOL JSM 5800).

\section{Results and discussion}

Rice husk contains silica in hydrated amorphous form and cellulose which yields carbon when thermally decomposed. When such a product is further heated at high temperature $\left(>1400^{\circ} \mathrm{C}\right)$ a reaction occurs between silica and carbon resulting in the formation of $\mathrm{SiC}$. The possible reactions of such a process can be written as

$$
\begin{aligned}
& \mathrm{C}(s)+\mathrm{SiO}_{2}(s) \rightarrow \mathrm{SiO}(g)+\mathrm{CO}(g), \\
& \mathrm{SiO}_{2}(s)+\mathrm{CO}(g) \rightarrow \mathrm{SiO}(g)+\mathrm{CO}_{2}(g), \\
& \mathrm{C}(s)+\mathrm{CO}_{2}(g) \rightarrow 2 \mathrm{CO}(g), \\
& 2 \mathrm{C}(s)+\mathrm{SiO}(g) \rightarrow \mathrm{SiC}(s)+\mathrm{C}(g),
\end{aligned}
$$

resulting in the overall reaction

$$
\mathrm{SiO}_{2} \text { (amorphous) }+3 \mathrm{C} \text { (amorphous) } \rightarrow \mathrm{SiC}+2 \mathrm{CO} \text {. }
$$

In the plasma furnace the temperature increases rapidly. It has been observed that after $2 \mathrm{~min}$ the volatiles are removed. The XRD patterns of the plasma treated rice husk at various times are depicted in figure 2 . The 


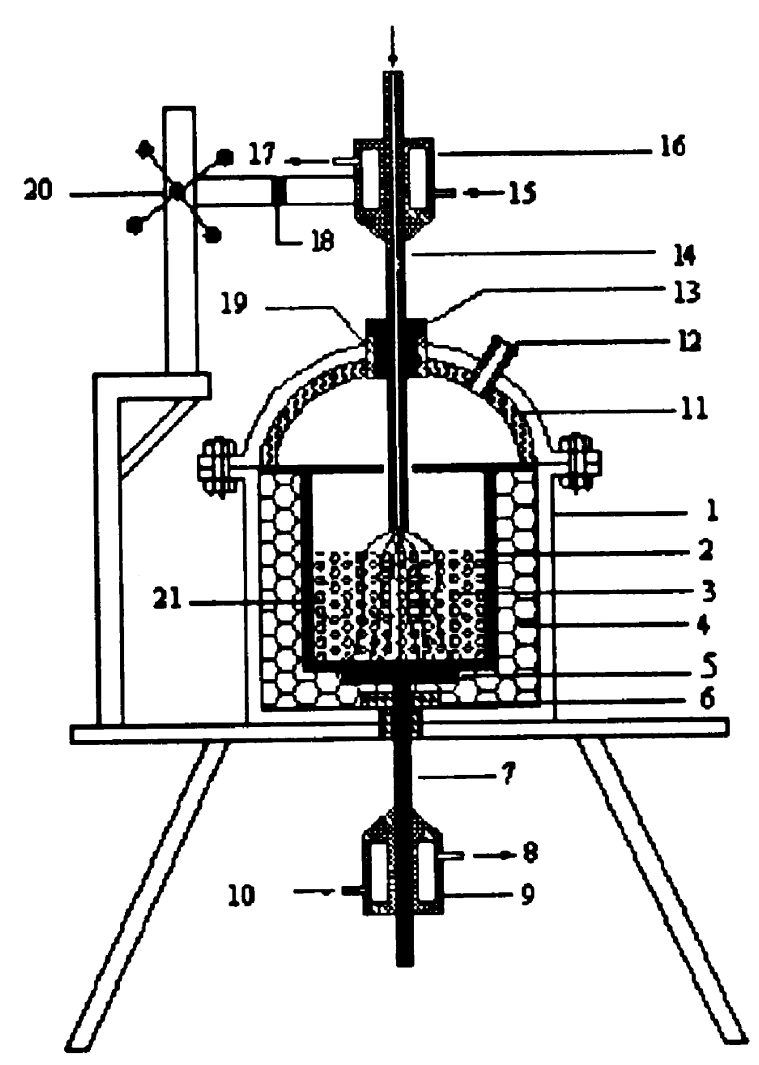

Figure 1. Schematic view of the plasma reactor (1. M.S. casing, 2. graphite crucible, 3. plasma, 4. bubble alumina, 5. graphite base, 6. alumina bush, 7. bottom electrode (graphite), 8. water outlet, 9. copper connector, 10. water in, 11. magnesia lining, 12. exhaust, 13. graphite bush, 14. top electrode (graphite), 15. water in, 16. copper connector, 17. water out, 18. electrical insulation, 19. alumina bush, 20. rack and pinion and 21 . charge).

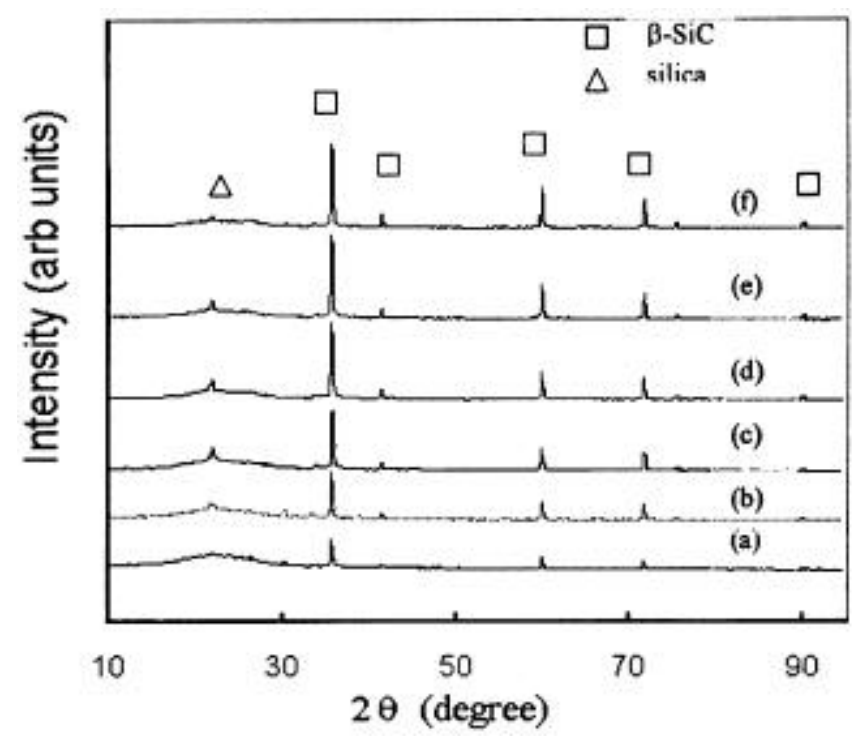

Figure 2. XRD patterns of plasma treated rice husk at various processing times: (a) $5 \mathrm{~min}$, (b) $10 \mathrm{~min}$, (c) $15 \mathrm{~min}$, (d) $20 \mathrm{~min}$, (e) $25 \mathrm{~min}$ and (f) $30 \mathrm{~min}$.
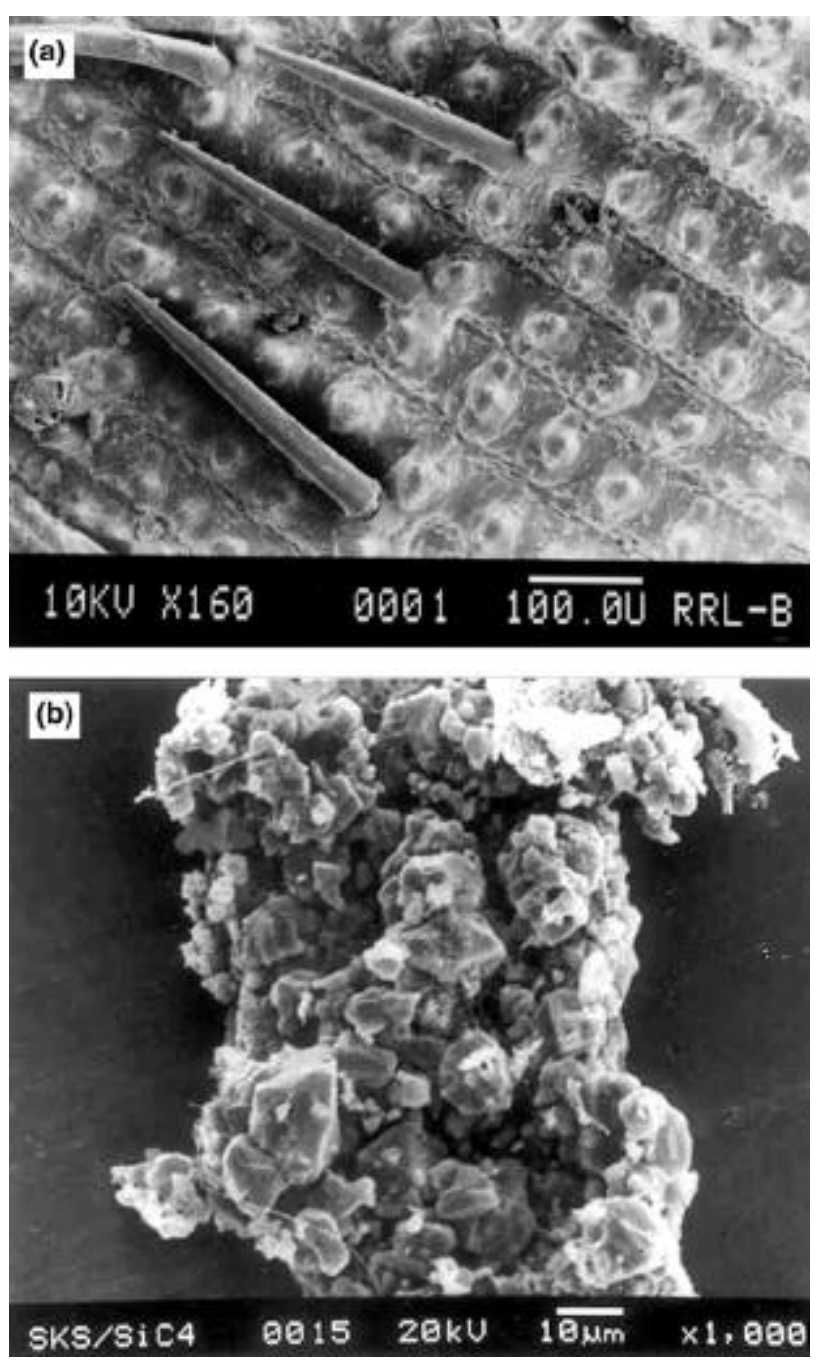

Figure 3. SEM micrographs of (a) raw and (b) plasma treated rice husk.

formation of $\beta$-SiC is observed even in a short time period of 5 min which suggests thermal plasma induced fast reaction due to the high temperature $\left(10^{4} \mathrm{~K}\right)$ associated with it. The reaction time of $20 \mathrm{~min}$ appears to be sufficient as there is not much change in the XRD pattern. Figures 3(a) and (b) show the SEM micrographs of the raw and plasma treated rice husk, respectively. The inorganic part is concentrated in the outer epidermis (outer face of the husk), where silica, which is in the amorphous form, is mainly concentrated in the regions of the 'horns' (Ray et al 1991). The formation of SiC crystals are clearly seen in figure $3(\mathrm{~b})$.

\section{Conclusions}

(I) To the best of our knowledge, thermal plasma has been utilized to convert raw rice husk to fine $\mathrm{SiC}$ for the first time.

(II) Thermal plasma can reduce the reaction time signi- 
ficantly as the formation of $\mathrm{SiC}$ is observed in a short time of 5 min.

\section{References}

Cutler I B 1973 US patent 3754079

Janghorban K and Tazesh H R 1999 Ceram. Int. 257

Krishnarao R V, Mahajan Y R and Kumar T J 1998 J. Euro. Ceram. Soc. 18147

Manosur N A L and Hanna S B 1979 Trans. J. Br. Ceram. Soc. 78132

Moustafa S F, Morsi M B and El-Din A A 1997 Can. Metall. Quar. 36355
Nutt S R 1988 J. Am. Ceram. Soc. 71149

Padmaja G and Mukunda P G 1999 J. Am. Ceram. Soc. 821393

Panigrahi M R and Overand R P 1997 in Proceedings of the third biomass conference of the american (ed.) R P Overend and E Chornet (New York: Elsevier Science, Inc.) p. 79

Panigrahi B B, Roy G G and Godkhindi M M 2001 Br. Ceram. Trans. 10029

Patel M 1991 Silicon Ind. 5530

Ray A K, Mohanty G and Ghose A 1991 J. Mater. Sci. Lett. 10277

Romera F J N and Reinso F R 1996 J. Mater. Sci. 31779

Singh S K, Stachowicz L, Girshick S L and Pfender E $1993 \mathrm{~J}$. Mater. Sci. Lett. 12659

Singh S K, Parida K M, Mohanty B C and Rao S B 1995 Reac. Kinet. Catal. Lett. 5429 